\title{
Examination of soluble integrin resistant mutants of foot-and-mouth disease virus
}

\author{
Paul Lawrence ${ }^{\dagger}$, Michael LaRocco ${ }^{\dagger}$, Barry Baxt and Elizabeth Rieder ${ }^{*}$
}

\begin{abstract}
Background: Foot-and-mouth disease virus (FMDV) initiates infection via recognition of one of at least four cell-surface integrin molecules $a_{v} \beta_{1}, a_{v} \beta_{3}, a_{v} \beta_{6}$, or $a_{v} \beta_{8}$ by a highly conserved Arg-Gly-Asp (RGD) amino acid sequence motif located in the G-H loop of VP1. Within the animal host, the $a_{v} \beta_{6}$ interaction is believed to be the most relevant. Sub-neutralizing levels of soluble secreted $a_{v} \beta_{6}\left(s_{s} a_{v} \beta_{6}\right)$ was used as a selective pressure during passages in vitro to explore the plasticity of that interaction.

Results: Genetically stable soluble integrin resistant (SIR) FMDV mutants derived from A24 Cruzeiro were selected after just 3 passages in cell culture in the presence of sub-neutralizing levels of $s_{s} a_{v} \beta_{6}$. SIR mutants were characterized by: replication on selective cell lines, plaque morphology, relative sensitivity to $s s_{v} \beta_{6}$ neutralization, relative ability to utilize $a_{v} \beta_{6}$ for infection, as well as sequence and structural changes. All SIR mutants maintained an affinity for $a_{v} \beta_{6}$. Some developed the ability to attach to cells expressing heparan sulfate (HS) proteoglycan, while others appear to have developed affinity for a still unknown third receptor. Two classes of SIR mutants were selected that were highly or moderately resistant to neutralization by $s s a_{v} \beta_{6}$. Highly resistant mutants displayed a G145D substitution (RGD to RDD), while moderately resistant viruses exhibited a L150P/R substitution at the conserved RGD + 4 position. VP1 G-H loop homology models for the A-type SIR mutants illustrated potential structural changes within the integrin-binding motif by these 2 groups of mutations. Treatment of $\mathrm{O} 1$ Campos with $\mathrm{ssa}_{\mathrm{v}} \beta_{6}$ resulted in $3 \mathrm{SIR}$ mutants with a positively charged VP3 mutation allowing for HS binding.

Conclusions: These findings illustrate how FMDV particles rapidly gain resistance to soluble receptor prophylactic measures in vitro. Two different serotypes developed distinct capsid mutations to circumvent the presence of sub-neutralizing levels of the soluble cognate receptor, all of which resulted in a modified receptor tropism that expanded the cell types susceptible to FMDV. The identification of some of these adaptive mutations in known FMDV isolates suggests these findings have implications beyond the cell culture system explored in these studies.
\end{abstract}

Keywords: Soluble receptor, $a_{v}$-integrin heterodimers, Foot-and-mouth disease virus (FMDV)

\section{Introduction}

Foot-and-mouth disease virus (FMDV) is responsible for the most economically important viral disease of cattle and other cloven-hoofed animals [1-5]. FMDV, the prototypic member of the Aphthovirus genus of Picornaviridae, utilizes in vitro four integrin heterodimers $\left(\alpha_{v} \beta_{1}, \alpha_{v} \beta_{3}, \alpha_{v} \beta_{6}\right.$, and $\alpha_{v} \beta_{8}$ ) for attachment to host cells and entry via clathrincoated pits (CCPs) [6-14]. A prominent surface-exposed loop connecting the $\beta \mathrm{G}-\beta \mathrm{H}$ strands (G-H loop) of the VP1

\footnotetext{
* Correspondence: elizabeth.rieder@ars.usda.gov

${ }^{\dagger}$ Equal contributors

Foreign Animal Disease Research Unit, United States Department of Agriculture, Agricultural Research Service, Plum Island Animal Disease Center, PO Box 848, Greenport, NY 11944-0848, USA
}

capsid protein contains a highly conserved Arg-Gly-Asp (RGD) motif, a recognition sequence for the $\alpha_{\mathrm{v}}$-integrin family of cell surface receptors [6,15-17]. Limited trypsin proteolysis removes the G-H loop, producing FMDV particles considerably less infectious relative to untreated virions, highlighting the importance of this region for productive infection [18-20]. Following integrin binding, CCPs internalize virus into acidic endosomes where uncoating occurs. FMDV field isolates continually passaged in cell culture adapt to utilize heparan sulfate (HS) as an alternative receptor, and exhibit attenuated pathogenicity [21-24].

Previously, soluble $\alpha_{\mathrm{v}} \beta_{3}$ and $\alpha_{\mathrm{v}} \beta_{6}$ lacking the transmembrane and cytoplasmic tail domains were shown to

\section{Biomed Central}


still function as FMDV receptors [25]. Pre-treatment of serotype A and O FMDV particles with soluble secreted bovine $\alpha_{v} \beta_{3}$ and $\alpha_{v} \beta_{6}$ prior to application on permissive cell lines was investigated as an antiviral therapy. Interestingly, only soluble $\alpha_{v} \beta_{6}$ limited FMDV attachment to host cells by competing for receptor binding sites on virus particles. Soluble $\alpha_{\mathrm{v}} \beta_{3}$ exhibited a low affinity interaction with the virus particles and failed to attach to FMDV in the same manner as $\alpha_{v} \beta_{6}$ with no significant effect on infectivity. It remains to be determined whether binding to blocking molecules such as soluble receptor, will impact FMDV interaction with the cellmembrane receptor or affect viral growth.

Here, we conducted in vitro experiments to evaluate the selective pressure exerted by soluble receptor protein on FMDV attachment and examined the evolution of virushost cell interactions. Studies conducted with poliovirus and its cognate receptor [26,27] showed that surface and internal capsid residues regulate attachment to the receptor and conformational change of the virus. Here, subneutralizing levels of soluble secreted bovine $\alpha_{v} \beta_{6}\left(s s \alpha_{v} \beta_{6}\right)$ were used to develop soluble receptor resistant mutants of FMDV A24 Cruzeiro. Of the $4 \alpha_{\mathrm{v}}$-integrins used by FMDV for host cell attachment, the $\beta_{6}$ heterodimer was selected on the basis that $\operatorname{ss}_{\mathrm{v}} \beta_{6}$ most substantially impeded FMDV infection [25]. Additionally, the $\beta_{6}$ heterodimer was shown to be most responsible for the tissue tropism of FMDV in cattle [28]. Following 3 successive passages of FMDV (serotype A and serotype O) pre-treated and co-incubated with $s s \alpha_{v} \beta_{6}$ on the LFBK cell line, which is permissive to infection by all 7 serotypes of FMDV (Figure 1, Table 1) [29], virus was isolated that persisted despite the presence of soluble integrin (SI). The A-type isolates exhibited mutations in the normally conserved RGD motif or just outside of it within the G-H loop of VP1, while the O-type mutants displayed changes in VP3 and residues proximal to the VP1 RGD motif. SI resistant (SIR) FMDV mutants were further characterized for altered receptor tropism, relative sensitivity to neutralization by $\mathrm{SI}$, as well as sequence and structural alterations in the G-H loop.
Table 1 Receptor repertoire of tested cell lines

\begin{tabular}{|c|c|c|c|c|c|c|}
\hline $\begin{array}{l}\text { Cell } \\
\text { Line } \\
\end{array}$ & $\operatorname{av} \beta 1$ & $\operatorname{av} \beta 3$ & $\operatorname{av} \beta 6$ & av $\beta 8$ & HS & Reference \\
\hline LFBK & + & + & + & $*$ & + & Figure 1 (this paper); [29] \\
\hline $\begin{array}{l}\mathrm{CHO} \\
\mathrm{K} 1\end{array}$ & - & - & - & - & + & {$[30-37]$} \\
\hline $\begin{array}{l}\mathrm{CHO} \\
677\end{array}$ & - & - & - & - & - & {$[21,30,38-41]$} \\
\hline IBRS2 & - & - & - & + & - & {$[16,42]$} \\
\hline $\cos -1$ & * & - & - & - & + & $\begin{array}{l}\text { Figures } 3 \text { and } 6 \text { (this paper); } \\
{[7,36,37]}\end{array}$ \\
\hline
\end{tabular}

\footnotetext{
${ }^{+}$Confirmed expression of the receptor molecule on the cell line indicated. - Confirmed lack of expression of the receptor molecule on the cell line indicated.

* Unclear if the receptor molecule is expressed on the cell line indicated. The receptor profile of $a_{v} \beta_{1}, a_{v} \beta_{3}, a_{v} \beta_{6}, a_{v} \beta_{8}$, and HS on 6 cell lines used was tabulated with references to studies that directly demonstrated the receptor profile or did so indirectly by virus growth profiles.
}

\section{Results}

Selection of FMDV serotype A SIR mutants

To examine the adaptability of serotype A FMDV (represented by A24 Cruzeiro) to the presence of soluble receptor during infection, we employed $s \alpha_{\mathrm{v}} \beta_{6}$, which is preferentially exploited by serotype A FMDV for host cell attachment $[7,25]$. As previously described, ectodomains of $\alpha_{v}$ and $\beta_{6}$ integrin subunits were secreted from stably transfected cells, which were properly folded and capable of heterodimerization (data not shown) [25]. The bovine kidney LFBK cell line was selected for these studies on the basis that it is susceptible to infection by all 7 FMDV serotypes, similar to primary bovine kidney cell culture and [29]. Western blot analysis confirmed that LFBK cells express both $\beta_{3}$ and $\beta_{6}$ integrins (Figure 1, Table 1). As expected, CHO 677 cells $[30,38]$ did not express $\beta_{3}$ and $\beta_{6}$ integrins [21,30-33,39-41]. While BHK-21 cells expressed $\beta_{3}$ integrin, we were unable to detect the presence of $\beta_{6}$ integrin. As an additional control, RNA Helicase A (RHA), known to be expressed in all 3 cell lines, was also detected. By extension, these findings allowed for the potential that both $\alpha_{v} \beta_{3}$ and $\alpha_{v} \beta_{6}$ could be found on the surface of LFBK cells, which is consistent with repeated
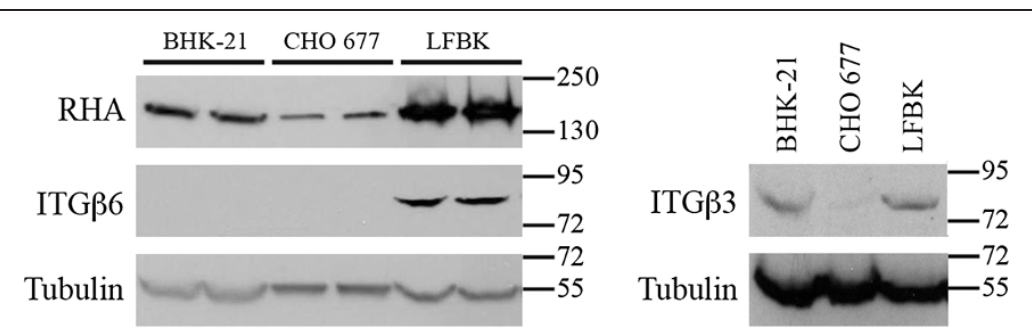

Figure 1 Integrin expression profile. BHK-21, CHO 677, and LFBK cell lysates were examined by Western blot probing with: anti- $\beta_{3}$ integrin (ITGB3), anti- $\beta_{6}$ integrin (ITG $\beta 6$ ), and anti-RHA. Equivalent loading between lanes was confirmed by probing with anti-tubulin-a. Molecular weight ladder bands are indicated. 
experiments showing the susceptibility of this cell line to non-HS-adapted field isolates of FMDV (data not shown).

Wild-type (WT) FMDV A24 Cruzeiro was preincubated with $10 \mu \mathrm{g} / \mathrm{mL} \mathrm{ss} \alpha_{\mathrm{v}} \beta_{6}$ (sub-neutralizing concentration for A24 Cruzeiro, Additional file 1: Figure S1) at $37^{\circ} \mathrm{C}$ for 1 hour prior to application of the coated virus on LFBK cells. As depicted in Figure 2A, LFBK cells were infected with $s s \alpha_{v} \beta_{6}$ coated WT FMDV A24 Cruzeiro at a MOI of 1 at $37^{\circ} \mathrm{C}$ for 24 hours (P1). Thirty-five plaques were isolated and used for a second round (P2) of infection with $\operatorname{ss}_{\mathrm{v}} \beta_{6}$. Only 17 of the 35 infections demonstrated cytopathic effects (CPE) at 24 hpi. Isolates from 17 P2 infections were individually used for a third selection (P3) with $s s \alpha_{v} \beta_{6}$. This resulted in only 4 productive infections derived from A24 Cruzeiro numbered: $15,23,42$, and 45 . The 4 soluble integrin resistant (SIR) serotype A (A-type) isolates (designated ASIR \#15, A-SIR \#23, A-SIR \#42, and A-SIR \#45) were subject to a final selection with $s s \alpha_{\mathrm{v}} \beta_{6}$, where by $24 \mathrm{hpi}$ A-type SIR isolates 15, 23, and 45 produced 100\% CPE and isolate 42 produced $50 \% \mathrm{CPE}$.

After multiple passages in cell culture, FMDV has been shown to gain the ability to attach to host cells via HS $[14,21-24,43]$. To determine if the A-type SIR mutants adapted to use HS for entry, replication of these viruses on LFBK and Chinese hamster ovary (CHO) $\mathrm{K} 1$ cells was compared. In contrast to LFBK cells, CHO K1 cells express HS, but not $\alpha_{v} \beta_{1}, \alpha_{v} \beta_{3}$ and $\alpha_{v} \beta_{6}$ (Table 1) [24,30-35]. Of note,

A

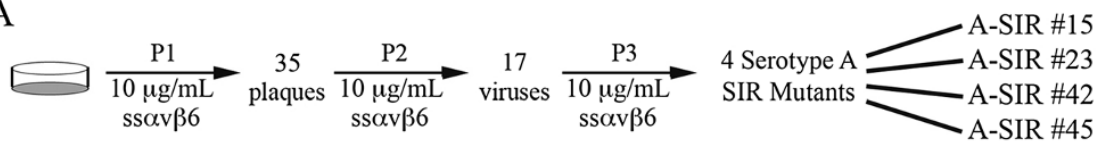

B
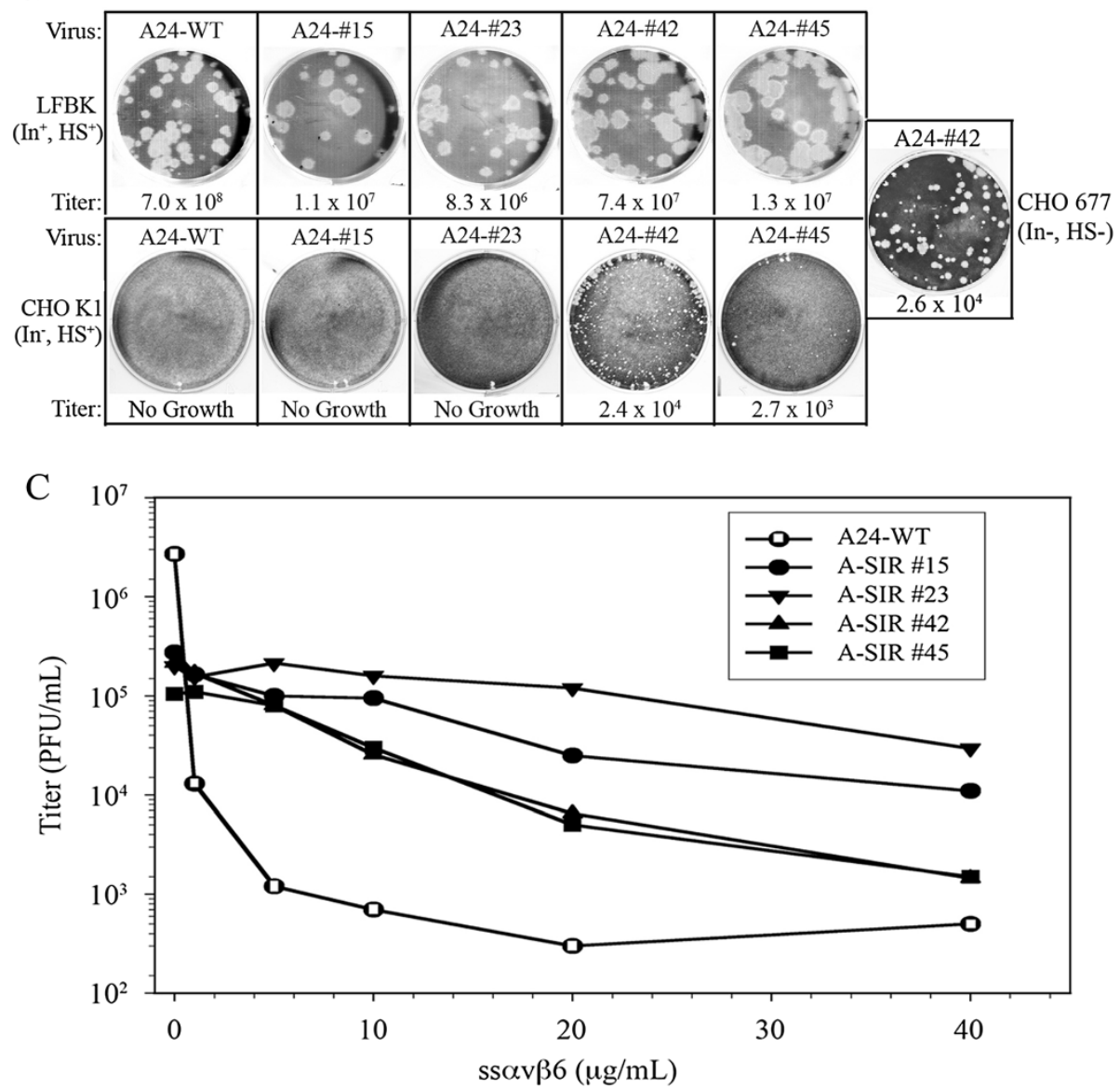

Figure 2 A-SIR mutant generation. A. Schematic of A-SIR mutant production. B. Comparison of the plaque morphology and titers achieved of A- SIRs relative to A24 Cruzeiro after pre-treatment and co-incubation with ssav $\beta_{6}$ on LFBK (top panel) and CHO K1 (bottom panel) cells for $24 \mathrm{~h}$. SIR \#42 was the only virus that amplified on CHO 677 cells (right box). Titers represent PFU/mL. C. WT and A-SIR viruses were co-incubated with increasing concentrations of $\mathrm{ssa}_{\mathrm{v}} \beta_{6}$ on LFBK monolayers for $24 \mathrm{~h}$, and the calculated titers were subsequently plotted. 
CHO K1 cells express 2 RGD-binding integrins $\left(\alpha_{5} \beta_{1}\right.$ and $\left.\alpha_{\mathrm{v}} \beta_{5}\right)$, but neither function as FMDV receptors $[7,10,30]$. WT and A-SIR viruses successfully infected LFBK cells (Figure 2B, top panel). However, WT and A-SIRs \#15 and \#23 were unable to infect $\mathrm{CHO} \mathrm{K} 1$ cells. In contrast, ASIRs \#42 and \#45 productively infected CHO K1 cells (Figure 2B, bottom panel). Thus, we suggest that A-SIRs \#42 and \#45 circumvented $s s_{\mathrm{v}} \beta_{6}$ neutralization by expanding their receptor preference to include HS, as previously observed under other conditions with different FMDV serotypes [23,24].

The A-type SIR mutants diverged with respect to their plaque morphologies on different cell lines. WT and A-SIR mutants maintained relatively large plaque sizes on LFBK cells (Figure 2B, top panel). On CHO K1 monolayers, ASIRs \#42 and \#45 showed reduced plaque size relative to LFBK cells (Figure 2B, lower panel). Comparative viral growth on LFBK and $\mathrm{CHO} \mathrm{K} 1$ cells suggests some A-SIRs might utilize HS. To examine this further, the growth analysis was expanded to include the $\mathrm{CHO} 677$ cell line (Figure 1, Table 1) $[39,40,44]$. In addition, the IBRS2 cell line with a unique receptor profile where FMDV infection is initiated via $\alpha_{\mathrm{v}} \beta_{8}[9,16,42]$, was also examined (Table 1 ). IBRS2 cells were permissive to infection by WT and A-SIR viruses, growing to titers comparable to LFBK cells (Table 2). Interestingly, A-SIR \#42 productively infected CHO 677 cells (Figure 2B, Table 2). SIR \#42 grew to roughly equivalent titers on $\mathrm{CHO} 677$ and $\mathrm{CHO}$ K1 cells (Figure 2B, Table 2). Viral growth on $\mathrm{CHO} 677$ cells suggested this A-SIR mutant adapted to utilize an as yet unidentified and uncharacterized third FMDV receptor $[21,41]$. It was inferred that growth of A-SIR \#45 on CHO K1 cells but not $\mathrm{CHO} 677$ cells was indicative that this virus exploited HS. Different growth patterns for each ASIR mutant on different cell lines also suggested these viruses are genetically distinct. These findings illustrated the rapid adaptability (after only 3 passages) of serotype A FMDV to overcome interference with host cell attachment.

\section{A-SIR mutants exhibit reduced sensitivity to SI neutralization}

Next, the relative sensitivities of A-SIR mutants to $\operatorname{ss} \alpha_{v} \beta_{6}$ neutralization were examined relative to their WT counterpart. Each virus was pre-incubated with $\operatorname{ss}_{\mathrm{v}} \beta_{6}$ at gradually increasing concentrations $(5,10,20,30$, and $40 \mu \mathrm{g} / \mathrm{mL}$ ), applied to LFBK monolayers, and evaluated for reductions in virus titer. As shown in Figure $2 \mathrm{C}$, the four A-SIR mutants could be divided into 2 classes with respect to sensitivity to neutralization by $\operatorname{ss}_{\mathrm{v}} \beta_{6}$ : a highly resistant (\#15 and \#23, Class I) and a moderately resistant class (\#42 and \#45, Class II). A-SIRs \#15 and \#23 grew to titers 200-1000 fold higher than WT with increasing $\operatorname{ss}_{\mathrm{v}} \beta_{6}$, while mutants \#42 and \#45 exhibited titers 20-100 fold higher than WT (Figure 2C). Cumulatively, these findings reinforced the supposition that preand co-incubation of $\operatorname{ss} \alpha_{v} \beta_{6}$ acts as a selective pressure forcing FMDV particles to quickly select for resistance to the treatment.

\section{A-SIR mutants continue to utilize $a_{v} \beta_{6}$}

Since the A-SIR mutants exhibited reduced sensitivity to $\operatorname{ss} \alpha_{v} \beta_{6}$ neutralization, we investigated whether they exhibit an altered integrin preference: shifting from $\alpha_{v} \beta_{6}$ to another integrin or a non-integrin receptor. The capability of A-SIRs to infect cells expressing distinct integrins was tested using a previously established transient transfection-infection assay [45]. COS-1 cells do not support FMDV infection and lack integrins used by FMDV (Table 1) [7]. These cells were co-transfected with plasmids encoding the full-length $\alpha_{\mathrm{v}}$-integrin subunit and 1 of 4 different full-length $\beta$ subunits $\left(\beta_{1}, \beta_{3}\right.$, $\beta_{5}$, or $\beta_{6}$ ). Expression was confirmed by immunocytochemical staining (Figure 3A). Of note, the antibody used to detect the $\alpha_{v} \beta_{1}$ only recognizes the $\beta_{1}$ subunit; as such, positive staining may be reflective of other $\beta_{1}$ containing integrin heterodimers.

WT virus and A-SIR mutants were incubated on the cells transiently expressing integrin with ${ }^{35} \mathrm{~S}$-methionine. After 24 hours, levels of viral protein synthesis were evaluated by radioimmunoprecipitation (RIP) (Figure 3B). Based on the sets where FMDV proteins (3D, VP0, VP1-3) were detected, it could be inferred as to which integrin heterodimers was/were used by WT and A-SIR viruses to gain entry to COS-1 cells for replication. Consistent with previous reports, viral protein synthesis was detected for A24 Cruzeiro WT in cells

Table 2 Growth comparison of A24 Cruzeiro WT and A-type SIRs on 6 cell lines

\begin{tabular}{lcccccc}
\hline Virus & LFBK & CHO K1 & CHO 677 & CHO 677 av36 & IBRS2 \\
\hline A24-WT & $7 \times 10^{8}$ & - & - & $6.3 \times 10^{7}$ & $6 \times 10^{8}$ & COS-1 \\
A-SIR \#15 & $1.1 \times 10^{7}$ & - & - & $2.8 \times 10^{6}$ & $4 \times 10^{7}$ & - \\
A-SIR \#23 & $8.3 \times 10^{6}$ & - & - & $1.8 \times 10^{6}$ & $2 \times 10^{7}$ & - \\
A-SIR \#42 & $7.4 \times 10^{7}$ & $2.4 \times 10^{4}$ & $2.6 \times 10^{4}$ & $5.6 \times 10^{6}$ & $6.5 \times 10^{7}$ \\
A-SIR \#45 & $1.3 \times 10^{7}$ & $2.7 \times 10^{3}$ & - & $2 \times 10^{7}$ & $1 \times 10^{7}$ \\
\hline
\end{tabular}

Numerical values represent virus titers in plaque forming units per milliliter (PFU/mL).

Dashes indicate no plaque detected at the lowest dilution of virus tested (1/10). 


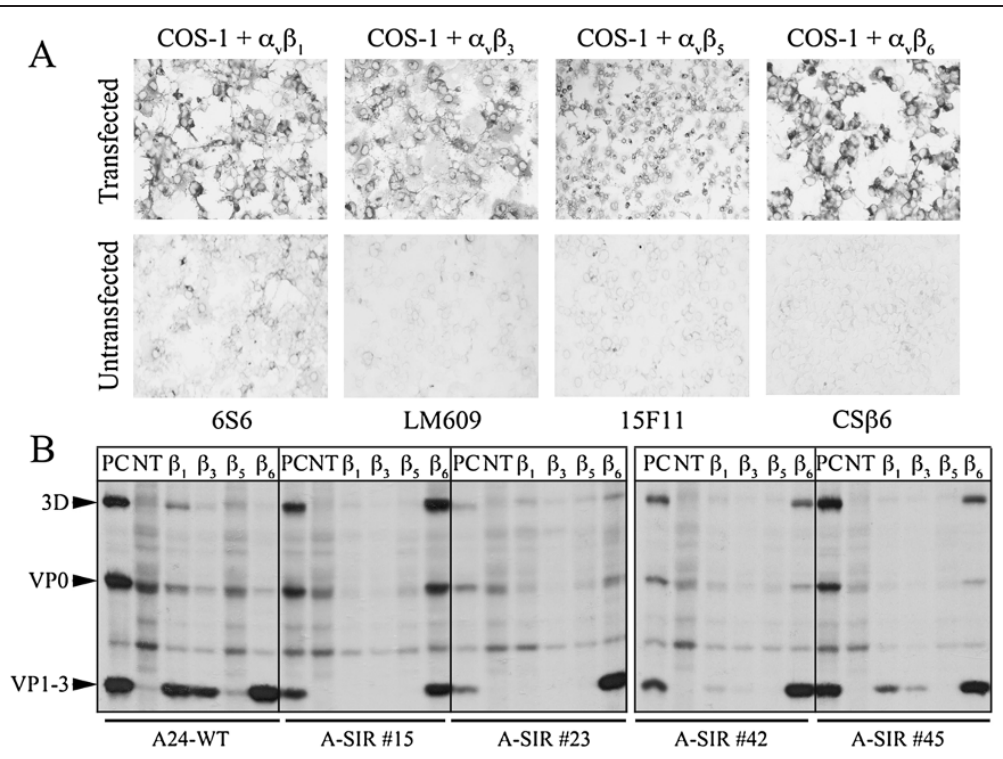

Figure 3 A-SIR mutants maintain $\boldsymbol{a}_{\mathbf{v}} \beta_{6}$ affinity. A. Expression of $\alpha_{v}$ and $\beta$ subunits $\left(\beta_{1}, \beta_{3}, \beta_{5}\right.$, or $\left.\beta_{6}\right)$ examined by immuno-histochemical staining using indicated antibodies. Untransfected cells probed as a negative control. B. RIP analysis of transfected cells infected with: A24 Cruzeiro and A-SIRs in the presence of ${ }^{35}$ S-methionine. NT, not transfected. PC, positive control: virus-infected LFBK cells.

expressing $\alpha_{\mathrm{v}} \beta_{1}, \alpha_{\mathrm{v}} \beta_{3}$ and $\alpha_{\mathrm{v}} \beta_{6}$ (Figure 3B) $[7,25]$. A-SIRs $\# 15$ and \#23 were only amplified on $\alpha_{v} \beta_{6}$ expressing cells. A-SIRs \#42 and \#45 infected cells displaying $\alpha_{\mathrm{v}} \beta_{1}$ and $\alpha_{v} \beta_{6}$. However, the signal for virus proteins was noticeably lower for A-SIR \#42 and \#45 relative to WT, though we cannot exclude the possibility that this was partially due to differences in transfection efficiencies. Besides WT, A-SIR \#45 was the only other virus able to infect via $\alpha_{v} \beta_{3}$. Interestingly, although resistant to neutralization by $\operatorname{ss} \alpha_{v} \beta_{6}$, all 4 A-SIR viruses replicated on $\alpha_{v} \beta_{6}$ expressing COS- 1 cells. Thus, it was inferred that all 4 A-SIR mutants maintained sufficient affinity for $\alpha_{v} \beta_{6}$ to continue to infect cells via this receptor.

To reinforce the supposition that the A-SIR viruses retained the ability to bind $\alpha_{v} \beta_{6}$, CHO 677 cells, which could not permit FMDV infection except for A-SIR \#42, were transiently transfected with $\alpha_{v} \beta_{6}$ as was done for COS-1 cells (data not shown). The expression of $\alpha_{v} \beta_{6}$ restored infectivity of WT and A-SIR viruses, with titers within 0.5 to $1 \log$ less than on LFBK cells (Table 2), with A-SIR \#45 attaining a titer 1 log higher than both class I SIRs. Notably, A-SIR \#42 achieved titers 2 logs higher than on untransfected $\mathrm{CHO} 677$ cells, suggesting $\alpha_{v} \beta_{6}$ is the preferred surface receptor for this virus.

\section{Amino acid substitutions detected in A-SIR mutants}

To further distinguish A-SIR viruses from their parental counterpart, A-SIR mutants were examined for alterations in their nucleotide and amino acid sequences relative to WT (Accession \#AY593768). No amino acid substitutions were detected in VP4, VP2, or VP3, with a single silent mutation detected in VP3. Interestingly, the
2 A-type SIR classes exhibited 2 corresponding types of mutations in VP1 summarized in Table 3 and Figure 4. Class I A-SIRs that were highly resistant to $\operatorname{ss}_{\mathrm{v}} \beta_{6}(\# 15$ and \#23) displayed a G145D amino acid substitution in the RGD motif considered essential for integrin interaction. The V154A substitution distinguished A-SIR \#23 from \#15. Class II A-type SIRs moderately resistant to $\mathrm{ss}_{\mathrm{v}} \beta_{6}$ (\#42 and \#45) exhibited substitutions at the RGD +4 position with L150P for \#42 and L150R for \#45. Moreover, A-SIR \#42 displayed 2 additional amino acid alterations upstream of the RGD motif: E95K and S96L. Previous reports have described the helical segment immediately C-terminal to the RGD motif as contributing to the interaction between FMDV and its cognate integrin receptor, specifically, amino acid positions RGD +1 and RGD + 4. The RGD + 1 and RGD + 4 side chains face out like those of the RGD motif and are frequently occupied by leucine residues $[8,14,46-49]$. While proline substitution at the RGD + 4 position was previously detected in the A5 Westerwald FRG/58 field isolate ([50] b; [51]) and serially passaged populations of a serotype C FMDV strain [21], the arginine substitution at this position appears unprecedented. Cumulatively, the P1 sequences support the findings that 2 distinct classes of SIR mutants were derived from A24 Cruzeiro: where each class exhibited distinct forms of amino acid substitutions localized to the VP1 G-H loop.

\section{Structural predictions of A-SIR mutant modifications}

After defining the amino acid changes within VP1 in the A-SIR mutants (Figure 4), we explored how those changes might affect the overall structure of the 
Table 3 Sequence comparison of the P1 region of A24 Cruzeiro and A-SIRs

\begin{tabular}{|c|c|c|c|c|c|c|c|c|c|}
\hline \multirow[t]{2}{*}{ Gene } & \multicolumn{3}{|c|}{ A24 Cruzeiro WT } & \multicolumn{3}{|c|}{ A-SIR \#15 and \#23 (Class I) } & \multicolumn{3}{|c|}{ A-SIR \#42 and \#45 (Class II) } \\
\hline & Nucleotide $^{a}$ & Codon $^{b}$ & Amino acid ${ }^{c}$ & Nucleotide $^{a}$ & Codon $^{b}$ & Amino acid ${ }^{c}$ & Nucleotide $^{a}$ & Codon $^{b}$ & Amino acid $^{c}$ \\
\hline VP2 & $\mathrm{C} 50$ & $\mathrm{cgG}$ & -— & -— & - - & -— & $\mathrm{G} 50^{45}$ & $\operatorname{cgA}$ & Silent \\
\hline VP1 & G6 & $\mathrm{acG}$ & - - & C6 & $\mathrm{acC}$ & Silent & C6 & $\mathrm{acC}$ & Silent \\
\hline VP1 & G283 & Gaa & E95 & -— & - - & - - & $\mathrm{A} 283^{42}$ & Aaa & K95 \\
\hline VP1 & $\mathrm{C} 287$ & $\mathrm{tCa}$ & S96 & - - & - - & - - & $\mathrm{T} 287^{42}$ & $\mathrm{tTa}$ & L96 \\
\hline VP1 & G434 & $g G c$ & G145 & A434 & gAc & D145 & - - & - - & - - \\
\hline \multirow[t]{2}{*}{ VP1 } & T449 & cTc & L150 & - - & - - & - & $\left(449^{42}\right.$ & $\mathrm{cCc}^{42}$ & $\mathrm{P} 150^{42}$ \\
\hline & & & & & & & $G 449^{45}$ & $c G c^{45}$ & $\mathrm{R} 150^{45}$ \\
\hline VP1 & T461 & gTc & V154 & $\left(461^{23}\right.$ & $\mathrm{gCc}$ & $\mathrm{A} 154^{23}$ & - & - & - \\
\hline
\end{tabular}

${ }^{a}$ Nucleotide differences between viruses followed by number indicating its position within the gene coding sequence.

${ }^{b}$ Lowercase letters indicate bases shared by the 2 viruses and capital letters indicate bases differing between the viruses.

c One-letter code of the encoded amino acid residues followed by number indicating residue position in the polypeptide.

P1 region of A24 Cruzeiro (Accession \# AY596768) was compared against: Class I (\#15 and \#23) and Class II (\#42 and \#45) A-SIRs. Nucleotide changes relative to

WT were indicated and codon positions. Silent mutations and amino acid substitutions are indicated. A-SIR mutant numerical designations were superscripted.

receptor-binding site in the G-H loop. The VP1 crystal structure has been solved for FMDV O1/BFS 1860/UK/ 67 (Accession 1FOD) [52]. Using the coordinates of $1 \mathrm{FOD}$ as a template, homology structures were generated of WT A24 Cruzeiro VP1 as well as those of the 4 A-SIR mutants using the Geno3D algorithm [53]. For each virus, 10 different "best fit" homology models were generated for VP1. Representative images of the G-H loop region were given particular scrutiny (Figure 5).

The RGD to RDD substitution detected in class I ASIR mutants \#15 and \#23 placed a bulky negatively charged residue into the center of the integrin binding site, which can be seen projecting outward in the homology structures generated. The introduction of D145 "spread out" the adjacent side chains within the RGD motif, increasing the distance between the R144 and D146 side chains relative to WT (Figure 5). In all 10 of the predicted tertiary structures, the amino acid alteration failed to effect any significant change in the backbone structure of this region of VP1.

The previously undetected L150R substitution at the RGD + 4 position of class II A-SIR \#45 replaces a linear non-polar amino acid side chain with a positively charged residue. Interestingly, Geno3D failed to predict a consensus structure for the A-SIR \#45 G-H loop. Class II A-SIR mutant \#42 exhibited a L150P substitution at RGD + 4, which was previously identified in FMDV A5 Westerwald FRG/58 [50,51]. The homology model of the A-SIR \#42 G-H loop revealed the proline residue introducing a kink that "compressed" the RGD motif with the three side chains in much closer proximity than WT (Figure 5). This structural prediction was essentially the opposite of what was produced for the class I A-SIR mutants.

In addition to L150P, A-SIR \#42 also displayed 2 substitutions upstream of the RGD: E95K and S96L, which are proximal to the VP1-VP3 interface. Using Geno3D, ribbon diagrams were generated of capsid protomers from WT and A-SIRs to determine if the protein interface was disrupted (Additional file 2: Figure S2). A short helical domain observed at the VP1-VP3 interface in the WT sequence was notably absent with the E95K/S96L substitution, replaced with a loop structure. With L150P previously detected in A5 Westerwald, E95K/S96L may be more significant to the adaptation of A_SIR \#42. We concluded that the mutations elucidated in the A-SIR

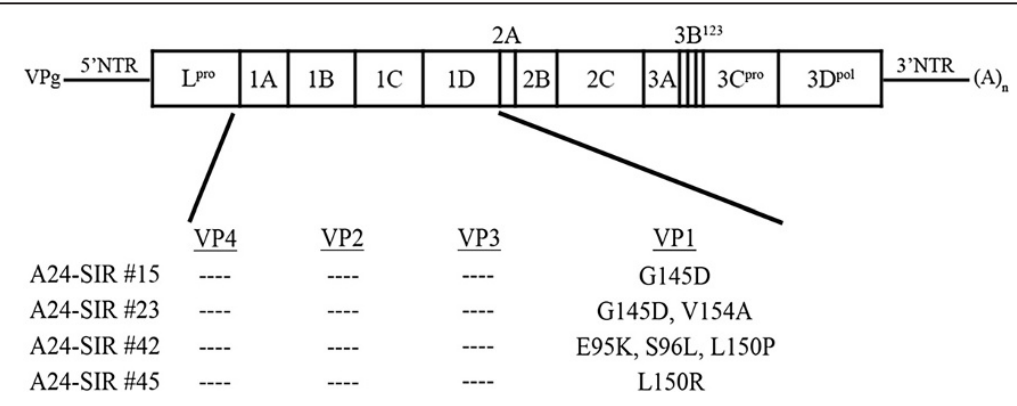

Figure 4 Amino acid substitutions within the P1 region of A-SIR mutants. Schematic of the FMDV genome summarizing the amino acid substitutions identified in the P1 region of A-SIR mutants after viral RNA from A24 Cruzeiro and A-SIRs was sequenced for amino acid substitutions in P1. 


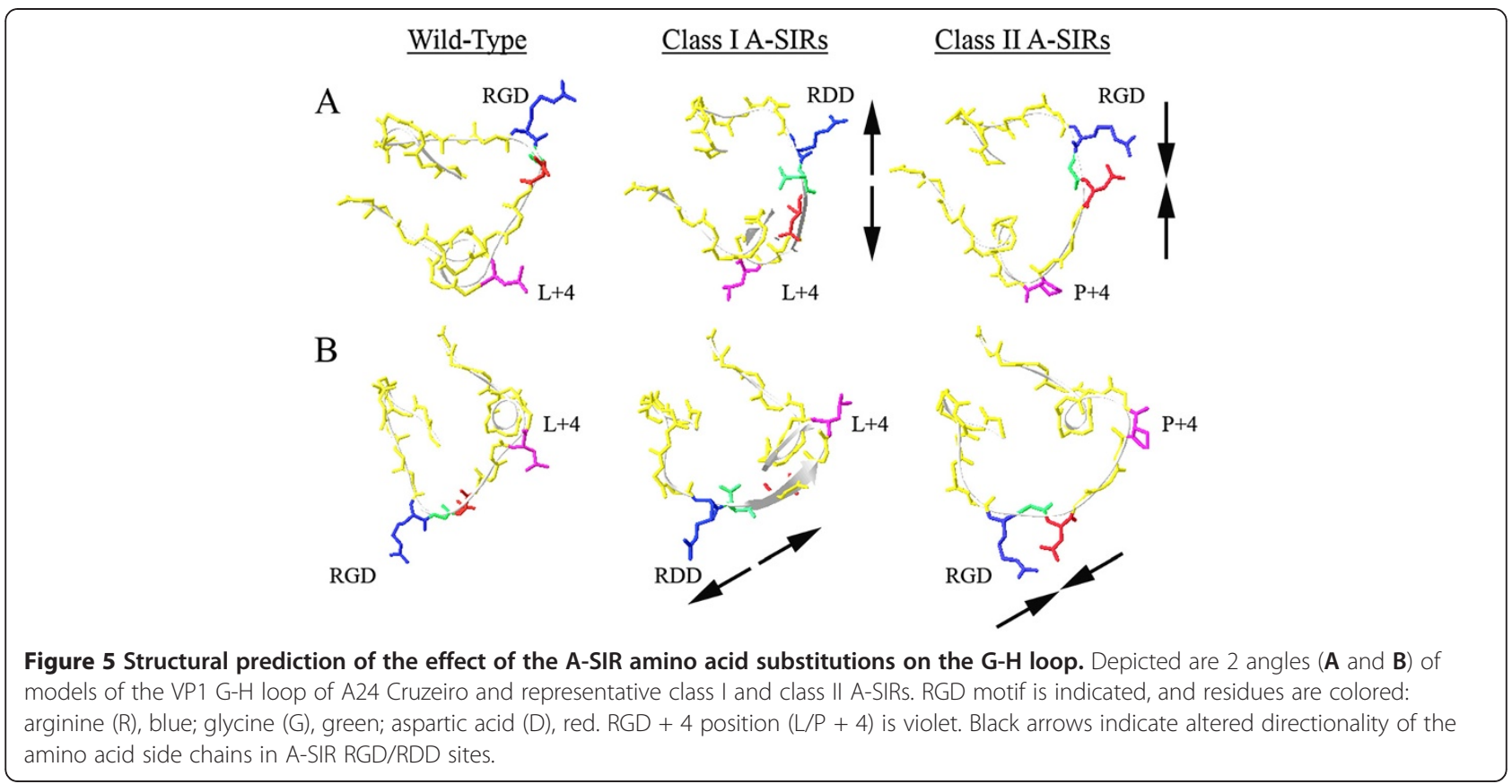

mutants produce hypothetical structural alterations likely to affect cellular recognition.

\section{Campos derived SIR mutants circumvent $s s a_{v} \beta_{6}$ by a different mechanism}

A-SIR mutants derived from A24 Cruzeiro overcame the selective pressure introduced by $\operatorname{ss}_{\mathrm{v}} \beta_{6}$ by compensatory mutations targeted to the RGD motif or the RGD + 4 position within the VP1 G-H loop. In an effort to determine if a similar strategy would be exploited by a different FMDV serotype, the experiment was repeated whereby $\mathrm{O} 1 \mathrm{Campos}$ was pre-treated and passaged three times in the continued presence of $10 \mu \mathrm{g} / \mathrm{mL} \operatorname{ss}_{\mathrm{v}} \beta_{6}$ (also a sub-neutralizing concentration for O1 Campos, data not shown). Three O-type SIR viruses were recovered designated O-SIR \#1, O-SIR \#9, and O-SIR \#46 (Figure 6A). All three O-SIRs produced similar small plaque forming units on LFBK cells relative to their WT progenitor (Figure 6B, top panel). Unlike the WT virus, the O-SIRs productively infected $\mathrm{CHO}$ K1 cells (Figure 6B, bottom panel), achieving titers approximately 1 log lower than on LFBK cells (Table 4). This suggested that the O-SIRs adapted to the presence of $\operatorname{ss}_{\mathrm{v}} \beta_{6}$ by selecting an affinity for HS, which represents a wellcharacterized strategy employed by serotype O FMDV $[22,23,54]$. Each O-SIR mutant produced distinct plaque morphologies on $\mathrm{CHO} \mathrm{K} 1$ cells; with large plaques for O-SIR \#1, medium-sized plaques for O-SIR \#9, and small pinprick plaques for O-SIR \#46 (Figure 6B, bottom panel). Interestingly, like the A-type SIR mutant \#42, OSIR \#9 could replicate, albeit to a limited titer, on $\mathrm{CHO}$
677 cells (Figure 6B, right panel and Table 4). When CHO 677 cells transiently expressing $\alpha_{\mathrm{v}} \beta_{6}$ were substituted in this assay, infectivity was restored for all O-SIR mutants and $\mathrm{O} 1$ Campos WT, with titers equivalent to or exceeding those on LFBK cells (Table 4). This particular finding was consistent with what was observed for the A-SIR viruses, where affinity for $\alpha_{v} \beta_{6}$ was maintained. Additionally, both O1 Campos and the O-SIR mutants demonstrated titers 1-2 logs higher on IBRS2 cells relative to LFBK cells (Table 4), which suggested that these viruses infect via $\alpha_{v} \beta_{8}$ with greater efficiency.

Further analysis revealed that all three O-SIRs were uniformly 2 logs more resistant to neutralization by $s s \alpha_{v} \beta_{6}$ up to $20 \mu \mathrm{g}$ of $s s \alpha_{v} \beta_{6}$ (Figure $6 \mathrm{C}$ ). However, while this resistance was maintained by O-SIR \#1 and O-SIR \#9 above $20 \mu \mathrm{g} \mathrm{ss} \alpha_{\mathrm{v}} \beta_{6}$, O-SIR \#46 was inhibited by ${ }^{s s} \alpha_{v} \beta_{6}$ at concentrations above $20 \mu \mathrm{g}$. Initial examinations of the reliance of the O-SIRs on different integrin heterodimers revealed the presence of FMDV proteins in untransfected COS-1 cells infected with the O-SIR mutants, similar to the pattern observed for O-SIR infected LFBK cells (Figure 6D). No increase in viral protein synthesis was observed for cells transiently expressing integrins (data not shown). Like CHO K1 cells, COS-1 cells express HS, thus it was inferred that the O-SIR mutants had circumvented $s s \alpha_{v} \beta_{6}$ neutralization by adapting to utilize HS for host cell attachment.

Given the disparities in plaque morphology and sensitivity to soluble integrin neutralization, it was expected that the O-type SIR mutants would be genetically distinct. In contrast to A-SIRs, compensatory mutations 
A

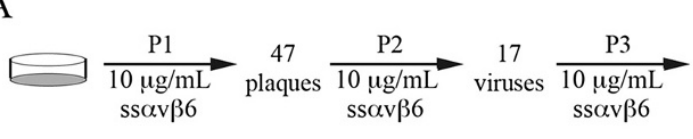

B

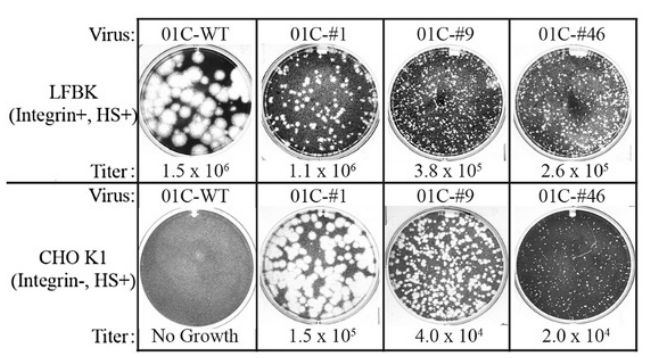

C 10

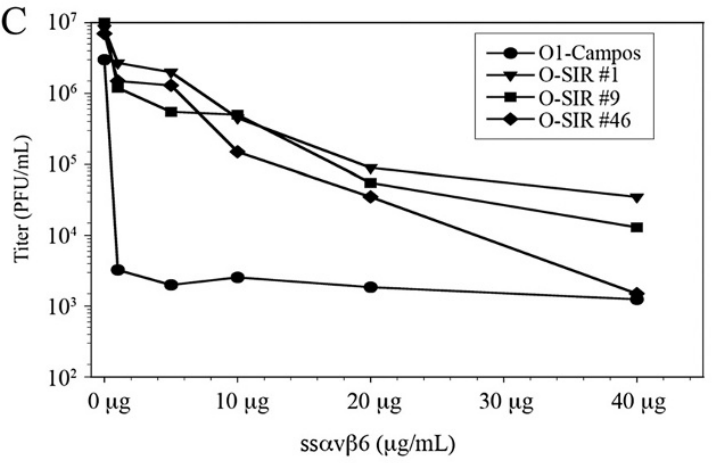

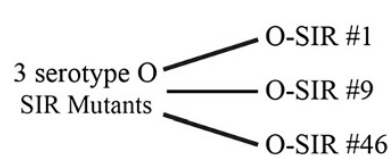

O-SIR \#46

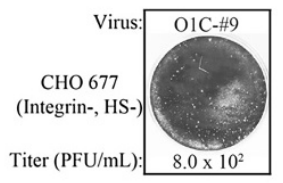

$\mathrm{D}$

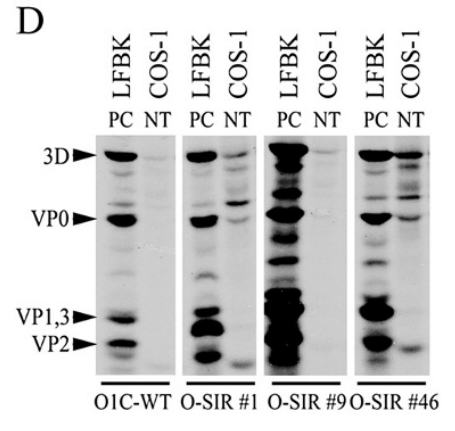

E

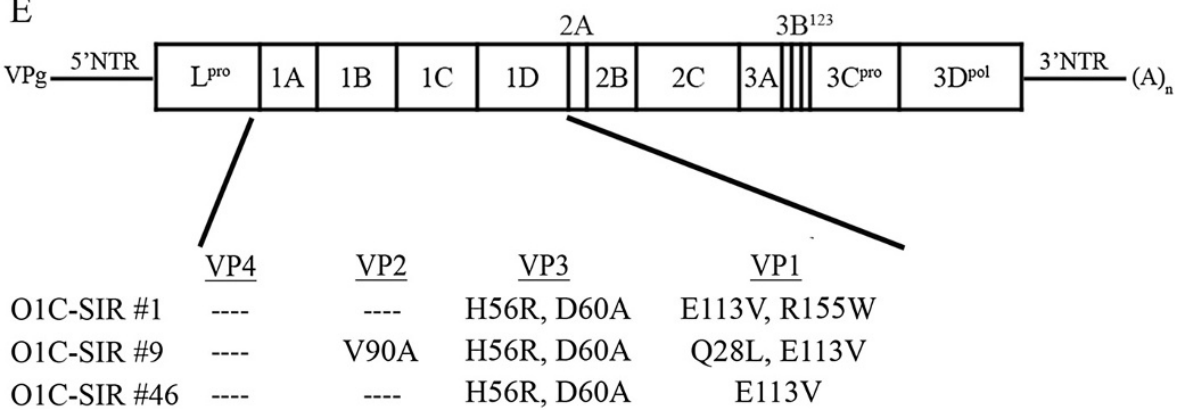

Figure 601 Campos derived SIR mutants exhibit distinctive alterations. A. Schematic of O1 Campos derived O-SIR mutant production. B. Comparison of the growth characteristics of O-SIRs relative to O1 Campos after ssa $\beta_{6}$ co-incubation on LFBK and CHO K1 cells. O-SIR \#9 was the only virus that amplified on $\mathrm{CHO} 677$ cells. Titers represent PFU/mL. C. WT and O-SIR viruses were co-incubated with ssa $\beta_{6}$ on LFBK monolayers for $24 \mathrm{~h}$, and the calculated titers were subsequently plotted. D. RIP analysis of untransfected LFBK and COS-1 cells infected with: O1 Campos and O-SIRs in the presence of ${ }^{35}$ S-methionine. NT, not transfected (COS-1). PC, positive control (LFBK). E. FMDV genome depicting amino acid substitutions identified in the P1 region of O-SIR mutants.

Table 4 Growth comparison of 01 Campos WT and O-type SIRs on 6 cell lines

\begin{tabular}{ccccccc}
\hline Virus & LFBK & CHO K1 & CHO 677 & CHO 677- av 36 & IBRS2 & COS-1 \\
\hline O1C-WT & $1.5 \times 10^{6}$ & - & - & $4 \times 10^{8}$ & $9 \times 10^{7}$ & - \\
O-SIR \#1 & $1.1 \times 10^{6}$ & $1.5 \times 10^{5}$ & - & $1.9 \times 10^{5}$ & $5 \times 10^{8}$ & $5 \times 10^{8}$ \\
O-SIR \#9 & $3.8 \times 10^{5}$ & $4 \times 10^{4}$ & $8.0 \times 10^{2}$ & $1.5 \times 10^{6}$ & $1.6 \times 10^{8}$ \\
O-SIR \#46 & $2.6 \times 10^{5}$ & $2 \times 10^{4}$ & - & $*$ \\
\hline
\end{tabular}

Numerical values represent virus titers in plaque forming units per milliliter (PFU/mL).

Dashes indicate no plaque detected at the lowest dilution of virus tested (1/10).

Asterisks indicate limited abortive infection without plaque formation, indicated by thinning of the cell monolayer. 
were not confined to VP1, but were also identified within VP3 (Figure 6E). The mutations detected in the O-SIRs were consistent with those previously found in HS-adapted serotype O FMDV passaged multiple times in cell culture with a signature H56R substitution in VP3 [22,23,54]. An additional D60A substitution in VP3 and an E113V substitution in the VP1 G-H loop were found in all O-SIR viruses. O-SIRs were distinguished from each other by 2 unique amino acid substitutions: R155W in the VP1 G-H loop of O-SIR \#1 and Q28L in VP1 and V90A in VP2 of O-SIR \#9. Notably, the conserved RGD motif and RGD +4 amino acid positions were unchanged.

Cumulatively, the development and characterization of the A-SIR and O-SIR FMDV mutants and the evolution of the virus-host interaction under the selective pressure of soluble integrin treatment was determined in the present study.

\section{Discussion}

Distinct lineages of RNA viruses are frequently referred to as "quasi-species" due to their inherent mutability $[47,55]$. Their rapid adaptability stems from the lack of "proofreading" function in the RNA-dependent RNA polymerases responsible for amplification of RNA viral genomes. The poliovirus RNA polymerase delivers approximately 1 error in 2200 bases, which is significant for a virus genome of approximately 7500 nucleotides [56]. Constant variation with each duplicated RNA viral population represents a stumbling block in the development of anti-viral therapies. A previous study explored using soluble receptor treatments to impair FMDV infection $[25,49]$. Here, we investigated the effect of subneutralizing levels of soluble secreted $\alpha_{\mathrm{v}} \beta_{6}\left(\operatorname{ss}_{\mathrm{v}} \beta_{6}\right)$ on FMDV replication in cells and documented the rapid emergence of resistant FMDV populations, how they circumvented the selective pressure of $\operatorname{ss}_{\mathrm{v}} \beta_{6}$, and the strategies deployed as they adapted.

Previous studies have investigated the effect of multiple passaging in cell culture on FMDV acquisition of alternative receptors, attenuated phenotypes, and for the dispensability of the RGD motif [21,49,57]. For instance, following 100 passages of a serotype C FMDV (C-S8c1) in cell culture, the virus was able to enter cells by an integrin-independent manner and multiple mutations were identified in the variant genomes [21]. For serotype A12 virus, it has been shown that mutations obtained during adaptation of field (bovine) isolates to cell culture localize downstream of the RGD and those mutations appear to alter the affinity for the integrin receptor [49].

Here, four SI resistant (SIR) FMD viruses derived from A24 Cruzeiro and three derived from O1 Campos were rapidly selected after only 3 rounds of cell culture selection in the continued presence of $\operatorname{ss}_{\mathrm{v}} \beta_{6}$. The A-SIR mutants could be separated into 2 classes that were either highly or moderately resistant to neutralization by $\operatorname{ssc}_{\mathrm{v}} \beta_{6}$. Highly resistant A-SIRs (Class I) did not select $\mathrm{HS}$ as a secondary receptor and maintained $\alpha_{\mathrm{v}} \beta_{6}$ affinity. These variants displayed a G145D substitution in the highly conserved VP1 RGD motif. The moderately resistant A-SIRs (Class II) also retained $\alpha_{v} \beta_{6}$ affinity and appeared to either utilize HS or an as yet unidentified and uncharacterized third FMDV receptor. Moreover, similar to A24 Cruzeiro, all 4 A-SIR mutants were amplified on IBRS2 cells, indicating that the A-SIRs have maintained the ability to infect and replicate on cells expressing an abundance of $\alpha_{\mathrm{v}} \beta_{8}$, which can also function as a FMDV receptor $[9,16,42]$.

\section{Class I A-SIR Mutants}

A-SIR mutants appear to have circumvented $\operatorname{ss}_{\mathrm{v}} \beta_{6}$ treatment by 2 different routes. Substitution of an aspartic acid (G145D) in the RGD motif (Figure 4) rendered A-SIR \#15 and 23 (Class I) highly resistant to $s s \alpha_{v} \beta_{6}$ (Figure 2C) while paradoxically maintaining use of $\alpha_{\mathrm{v}} \beta_{6}$ for infection (Figure 3B). Notably, class I A-SIRs did not adapt to utilize HS. Interestingly, this RDD mutation in the cell receptor binding site has been detected in a field strain of Asia1 virus (Asia1/JS/CHA/05) after just 2 passages, one in vivo and one in vitro [57]. RDD Asial variants showed no change in their ability to replicate in established cell lines, nor did it alter clinical onset of disease in animals tested [57]. While the environmental pressure that selected for RDD Asia1 variants is unknown, it suggests that this mutation might be a natural adaptation mechanism that could manifest across different FMDV serotypes. This hypothesis is supported by the observation that natural outbreaks of serotype A FMDV featuring the RDD amino acid substitution have occurred in Argentina on two occasions: A25-Arg/59 (GenBank \#AY593769) and A25-Arg/ 61 (GenBank \#AY593789).

The likely reason for the selection of a modified RGD was also investigated using homology models of the VP1 G-H loop structure and position of the RDD side chains (Figure 5). The data showed an additional negative charge provided by G145D widened the gap between the side chains of R144 and D146. Potentially, the widening of the RDD side chains or the introduction of an additional negatively charged side chain might diminish the affinity of the motif for the integrin by sterically complicating the binding of $s s \alpha_{v} \beta_{6}$, which is not anchored to a membrane, to the virus particle during pre-treatment in solution. Correspondingly, by reducing the affinity but not ablating the interaction with $\alpha_{v} \beta_{6}$ (Figure 3B, Table 2), unoccupied RDD sites on the virus particle after pre-treatment and subsequent co-incubation with $\mathrm{ss}_{\mathrm{v}} \beta_{6}$ likely allow infection of host cells via $\alpha_{\mathrm{v}} \beta_{6}$. 


\section{Class II A-SIR Mutants}

In contrast, moderately resistant Class II A-SIRs left the RGD intact, but substituted a key amino acid at the RGD + 4 position $[8,14,46-48]$, with the conserved leucine replaced with proline for A-SIR \#42 and arginine for A-SIR \#45. L150P was previously identified in FMDV A5 Westerwald FRG/58 [50,51] as well as a multiply passaged serotype C FMDV [21,58]. However, L150R appears unprecedented. Interestingly, while both viruses replicated in $\mathrm{CHO} \mathrm{K} 1$ cells, only A-SIR \#42 infected CHO 677 cells. However, both class II A-SIRs exhibited preference for $\alpha_{\mathrm{v}} \beta_{6}$ over alternative surface molecules (Figure 2, Table 2). Given L150P was previously detected in the WT field strain A5 Westerwald [51], it will be interesting to explore in the future whether this amino acid alteration was solely responsible for shifting receptor tropism to allow infection of cells devoid of FMDV integrin receptors and HS [21,30,38,41]. However, two additional mutations detected in VP1, E95K and S96L, might also contribute or be exclusively responsible for the A-SIR \#42 phenotype.

Homology modeling was also employed to illustrate how Class II amino acid substitutions affected both the G-H loop (Figure 5) and the capsid protomer (Additional file 2: Figure S2). In contrast to Class I A-SIRs, L150P appears to compress the side chains projecting from the RGD motif, where R144 and D146 are in closer proximity than in A24 Cruzeiro or Class I A-SIRs (Figure 5). The unique E95K/ S96L substitutions localized to the VP1-VP3 interface, potentially altering capsid protomer stability (Additional file 2 : Figure S2). Modeling algorithms failed to generate a consensus structure for the G-H loop of A-SIR \#45, where multiple potential side chain angles for L150R altered the shape and presentation of the RGD motif (data not shown).

\section{O-SIR mutants}

When the approach used to generate the A-SIRs was applied to O1 Campos, this resulted in three distinctive OSIR mutants that bind to HS and that carried a signature H56R mutation. This particular mutation has been observed in attenuated HS-adapted FMDVs [22,23,54]. Similar to their A-type counterparts, the O-SIRs also could be amplified on IBRS2 cells suggesting that the selective pressure of co-incubation with $\operatorname{ss}_{\mathrm{v}} \beta_{6}$ did not abrogate the affinity for $\alpha_{\mathrm{v}} \beta_{8}$. However, unlike A24 Cruzeiro and the A-SIRs, O1 Campos and the O-type SIR mutants amplified 2-3 logs more in IBRS2 cells relative to LFBK cells, thus it could be inferred that serotype O FMDV may have a preference for $\alpha_{\mathrm{v}} \beta_{8}$ as a receptor. As such it would be intriguing to explore the effects of successive passages of $\mathrm{O} 1 \mathrm{Campos}$ in the presence of $\operatorname{ss}_{v} \beta_{8}$ in the future. Lastly, it is interesting to note that the mutations accumulated by the O-SIRs were not in the VP1 RGD motif, but rather peripheral to it and at locations in VP3, separate from the primary site of attachment to the host cell.

\section{Conclusions}

Together the results of this study have shed light on the plasticity of FMDV serotype A and $\mathrm{O}$ interactions with its primary cognate receptor: $\alpha_{v} \beta_{6}$. Amino acid substitutions detected in SIR mutants were rapidly selected to overcome soluble receptor neutralization. Thus, the tolerance of the VP1 G-H loop to amino acid substitutions plays an essential role in cell receptor adaptability of FMDV. Interestingly, mutations identified in the current study have been also identified in FMDV field isolates causing outbreaks suggesting that similar selective pressures may exist in the natural host environment. The mode and relative speed with which FMDV was able to adapt to a selective pressure, represented here by $\operatorname{ss}_{\mathrm{v}} \beta_{6}$, highlights both the evolutionary advantage of highly mutable RNA viruses and the challenges of designing effective antiviral therapies against these pathogens.

\section{Materials and methods Materials}

Fugene- 6 was purchased from Roche (Nutley, NJ). Mouse monoclonal anti- $\beta_{3}$ integrin (ITG $\beta 3$ ) was purchased from Abcam (Cambridge, MA). Rabbit polyclonal anti- $\beta_{6}$ integrin (ITGB6) was purchased from Sigma (St. Louis, MO). Mouse monoclonal anti- $\beta_{1}$ integrin (6S6), anti- $\alpha_{v} \beta_{3}$ integrin (LM609), anti- $\alpha_{v} \beta_{5}$ integrin (15 F11), and anti- $\beta_{6}$ integrin (CS $\beta 6)$ was purchased from Millipore (Billerica, MA). Rabbit polyclonal anti-RHA was purchased from Bethyl Laboratories (Montgomery, TX).

\section{Cells, viruses, and plasmids}

IBRS2, COS-1, and 293a cell lines purchased from American Tissue Collection Company (ATCC; Manassas, VA) were cultured in Dulbecco's minimal eagle medium (DMEM) with $10 \%$ fetal bovine serum (FBS) at $37^{\circ} \mathrm{C}$ with $5 \% \mathrm{CO}_{2}$. LFBK cell line was previously described [29], and cultured in DMEM with $10 \% \mathrm{FBS}$ at $37^{\circ} \mathrm{C}$ with $5 \% \mathrm{CO}_{2}$. $\mathrm{CHO} \mathrm{K} 1$ and 677 cell lines were acquired from Dr. Jeffrey Esko [39] and cultured in Ham's MEM (Gibco) with 10\% FBS at $37^{\circ} \mathrm{C}$ with $5 \% \mathrm{CO}_{2}$. FMDV A24 Cruzeiro field strain was derived from pA24-Cru [59]. FMDV O1 Campos field strain was previously described [24].

\section{SI production}

Expression and purification of $\operatorname{ss}_{\mathrm{v}} \beta_{3}$ and $\operatorname{ss}_{\mathrm{v}} \beta_{6}$ was previously described [25]. Plasmids encoding ectodomains of integrin subunits $\left(\alpha_{v}, \beta_{3}\right.$, and $\left.\beta_{6}\right)$ were transfected using Fugene-6 (Roche) per manufacturer's instructions. Stable expression was selected by incubating with G418 $\left(\alpha_{v}\right.$ gene sub-cloned into pcDNA3.1-G418) and zeomycin $\left(\beta_{3}\right.$ and 
$\beta_{6}$ gene sub-cloned into pcDNA3.1-Zeo). Supernatants were collected and concentrated 10-fold using Centricon Plus-70 filter devices (Millipore, Billerica, MA). Subsequent protein concentration measured between $125-250 \mu \mathrm{g} / \mathrm{mL}$.

\section{Radio-immunoprecipitation (RIP)}

Virus-infected cells grown overnight in the presence of ${ }^{35} \mathrm{~S}$-methionine were lysed with $1 \%$ Triton X100. Aliquots of each sample were precipitated with $20 \%$ trichloroacetic acid (TCA) to determine the counts per minute $(\mathrm{cpm})$. Lysates were mixed with Protein A/G agarose beads, tumbled 15 minutes, centrifuged at $1500 \mathrm{rpm} 10$ minutes, and the supernatants collected. Recovered supernatant was tumbled with indicated antibodies (6S6, LM609, $15 \mathrm{~F} 11$, and CS 36 ) 1 hour at $4^{\circ} \mathrm{C}$. The mixture was tumbled overnight at $4^{\circ} \mathrm{C}$ with fresh Protein A/G agarose. Afterwards, the agarose was washed 3 times with $\mathrm{NET} / \mathrm{NP} 40$ buffer $(\mathrm{NaCl}$, EDTA, Tris, Nonidet-P40). Finally, the agarose was boiled in sample buffer without $\beta$-mercaptoethanol, pelleted, the supernatants separated by SDS-PAGE, and the gel examined by autoradiography.

\section{Transient transfection-infection assay}

Assay was conducted as previously described [45]. Two sets of COS-1 or CHO 677 cells were transfected with 2 plasmids: one encoding full-length $\alpha_{\mathrm{v}}$-integrin subunit and the other encoding 1 of 4 different full-length $\beta$ subunits $\left(\beta_{1}, \beta_{3}, \beta_{5}\right.$, or $\left.\beta_{6}\right)$. The first sets were examined by immuno-histochemical staining to confirm expression, using antibodies: 6S6 $\left(\alpha_{\mathrm{v}} \beta_{1}\right)$, LM609 $\left(\alpha_{\mathrm{v}} \beta_{3}\right), 15$ F11 $\left(\alpha_{\mathrm{v}} \beta_{5}\right)$, and $\operatorname{CS} \beta 6\left(\alpha_{\mathrm{v}} \beta_{6}\right)$. 6S6 binds the $\beta_{1}$ subunit and COS-1 cells express $\alpha_{5} \beta_{1}$, which is not a cellular receptor for FMDV [11,12,21]. The other sets were infected with WT and SIR viruses at a MOI of 1 in ${ }^{35}$ S-methionine containing media. Subsequently, virus-infected cell lysates were examined by RIP for virus-specific bands: 3D, VP0, and VP1-3.

\section{Virus titer assay}

One hour post-adsorption, the inoculum was removed, and cells washed in a mild acid solution followed by virus growth media (VGM, DMEM containing L-glutamine). VGM was then added and cells incubated 24 hours at $37^{\circ} \mathrm{C}$. Afterwards, virus-infected cells were harvested and titers determined by plaque assay as previously described [60]. Plates were fixed, stained with crystal violet $(0.3 \%$ in Histochoice; Amresco, Solon, $\mathrm{OH}$ ), and plaques counted. Values calculated for number of plaque-forming units (PFUs) per milliliter $(\mathrm{mL})$ were plotted using Microsoft Excel (Microsoft Corporation, Redmond, WA). Assays were performed in triplicate.

\section{Western blot}

Protein samples were separated by $\mathrm{Nu}-\mathrm{PAGE}{ }^{\circledR}$ pre-cast gel system (Invitrogen), and electro-blotted onto nitrocellulose (Sigma). After blocking with 5\% milk, proteins were detected with indicated primary integrin antibodies (anti- $\beta_{3}$, Abcam and anti- $\beta_{6}$, Sigma) followed by HRPconjugated goat-anti-mouse or goat-anti-rabbit antibodies (Bethyl Laboratories), respectively. Cellular tubulin, employed as a loading control, was detected with HRP-conjugated anti-tubulin- $\alpha$ (Abcam, Cambridge, MA). HRP was reacted with WestDura SuperSignal chemiluminescent reagent (Pierce) and visualized on Xray film (X-Omat; Kodak, N.Y., USA).

\section{Sequencing of the FMDV P1 Region}

The P1 region in twenty FMDV isolates were sequenced from PCR product with sequencing primers providing at least $3 \mathrm{X}$ coverage across 3,000 base pairs. PCR products were purified with QIAQuick spin columns (Qiagen) in accordance with the manufacturer's instructions. Sequencing reaction mixtures $(10 \mu \mathrm{l})$ contained $2.5 \mu \mathrm{M}$ primer, $20 \mathrm{ng}$ of PCR product, and $0.75 \mu \mathrm{l}$ of Big Dye (Applied Biosystems) in molecular biology-grade water. The sequence cycling conditions were $30 \mathrm{~s}$ of preincubation at $85^{\circ} \mathrm{C} ; 25$ cycles of $10 \mathrm{~s}$ at $96^{\circ} \mathrm{C}, 5 \mathrm{~s}$ at $50^{\circ} \mathrm{C}$, and $4 \mathrm{~min}$ at $60^{\circ} \mathrm{C}$; and a $10-\mathrm{min} 60^{\circ} \mathrm{C}$ final extension. The sequencing reaction mixtures were purified with Agencourt's CleanSEQ system in accordance with the manufacturer's instructions (Beckman Coulter).

\section{Structural analysis}

Amino acid sequences of SIRs were used to construct homology models of the G-H loop and capsid protomers using the Geno3D algorithm [53]. Ten most likely structures were generated using a solved structure as a template. Two $\mathrm{X}$-ray crystal structures for the major immunogenic site of FMDV designated 1FOD [52] and 1ZBE [61] in the Protein Data Bank (PDB) were selected as templates. Hypothetical structures were examined using DeepView [62,63], and a consensus structure for each sequence was selected.

\section{Additional files}

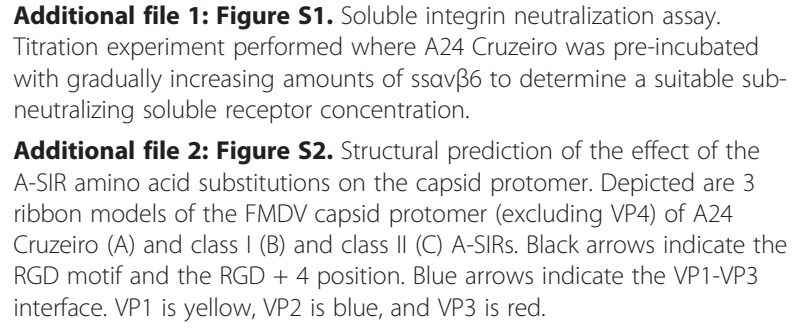

Additional file 2: Figure S2. Structural prediction of the effect of the A-SIR amino acid substitutions on the capsid protomer. Depicted are 3 ribbon models of the FMDV capsid protomer (excluding VP4) of A24 Cruzeiro (A) and class I (B) and class II (C) A-SIRs. Black arrows indicate the RGD motif and the RGD + 4 position. Blue arrows indicate the VP1-VP3 interface. VP1 is yellow, VP2 is blue, and VP3 is red.

\section{Competing interests}

The authors declare that they have no competing interests. 


\section{Authors' contributions}

PL: evaluated the integrin expression on the tested cell lines, organized the sequencing data and performed the sequencing alignments, constructed the structural models, and drafted the manuscript. ML: produced the FMDV SIR mutants, evaluated SIR plaque morphologies and growth kinetics on indicated cell lines, and performed the radio-immunoprecipitation analysis. BB: co-conceived the study and participated in its design and implementation. ER: co-conceived the study and participated in its design, implementation, and coordination. All authors have read and approved the final version of the manuscript.

\section{Acknowledgments}

We wish to thank Bill Hurtle for his expertise sequencing the capsid region of FMDV SIR mutants. We also wish to thank Drs. Devendra Rai and Francois Maree for fruitful discussions regarding structural analyses of the SIR mutants. Dr. Paul Lawrence was sponsored by the Plum Island Animal Disease Research Participation Program administered by the Oak Ridge Institute for Science and Education through an interagency agreement between the U.S Department of Energy and the U.S. Department of Agriculture.

Received: 5 July 2012 Accepted: 11 December 2012 Published: 2 January 2013

\section{References}

1. Domingo E, Baranowski E, Escarmis C, Sobrino F: Foot-and-mouth disease virus. Comp Immunol Microbiol Infect Dis 2002, 25:297-308.

2. Grubman MJ, Baxt B: Foot-and-mouth disease. Clin Microbiol Rev 2004, 17:465-493.

3. Mason PW, Grubman MJ, Baxt B: Molecular basis of pathogenesis of FMDV. Virus Res 2003, 91:9-32.

4. Saiz M, Nunez Jl, Jimenez-Clavero MA, Baranowski E, Sobrino F: Foot-and-mouth disease virus: biology and prospects for disease control. Microbes Infect 2002, 4:1183-1192

5. Sobrino F, Saiz M, Jimenez-Clavero MA, Nunez Jl, Rosas MF, Baranowski E, Ley $\mathrm{V}$ : Foot-and-mouth disease virus: a long known virus, but a current threat. Vet Res 2001, 32:1-30.

6. Baxt B, Becker Y: The effect of peptides containing the arginine-glycineaspartic acid sequence on the adsorption of foot-and-mouth disease virus to tissue culture cells. Virus Genes 1990, 4:73-83.

7. Duque $H$, Baxt B: Foot-and-mouth disease virus receptors: comparison of bovine alpha(V) integrin utilization by type $\mathrm{A}$ and $\mathrm{O}$ viruses. J Virol 2003, 77:2500-2511

8. Jackson T, Blakemore W, Newman JW, Knowles NJ, Mould AP, Humphries MJ, King AM: Foot-and-mouth disease virus is a ligand for the highaffinity binding conformation of integrin alpha5beta1: influence of the leucine residue within the RGDL motif on selectivity of integrin binding. $J$ Gen Virol 2000, 81:1383-1391.

9. Jackson T, Clark S, Berryman S, Burman A, Cambier S, Mu D, Nishimura S, King AM: Integrin alphavbeta8 functions as a receptor for foot-andmouth disease virus: role of the beta-chain cytodomain in integrinmediated infection. J Virol 2004, 78:4533-4540.

10. Jackson T, Mould AP, Sheppard D, King AM: Integrin alphavbeta1 is a receptor for foot-and-mouth disease virus. J Virol 2002, 76:935-941.

11. Jackson T, Sheppard D, Denyer M, Blakemore W, King AM: The epithelia integrin alphavbeta6 is a receptor for foot-and-mouth disease virus. $J$ Virol 2000, 74:4949-4956.

12. Neff S, Sa-Carvalho D, Rieder E, Mason PW, Blystone SD, Brown EJ, Baxt B: Foot-and-mouth disease virus virulent for cattle utilizes the integrin alpha(v)beta3 as its receptor. J Virol 1998, 72:3587-3594.

13. O'Donnell V, LaRocco M, Duque H, Baxt B: Analysis of foot-and-mouth disease virus internalization events in cultured cells. J Virol 2005, 79:8506-8518.

14. Ruiz-Saenz J, Goez Y, Tabares W, Lopez-Herrera A: Cellular receptors for foot and mouth disease virus. Intervirology 2009, 52:201-212.

15. Brown F, Benkirane N, Limal D, Halimi H, Newman JF, Van Regenmortel MH, Briand JP, Muller S: Delineation of a neutralizing subregion within the immunodominant epitope (GH loop) of foot-and-mouth disease virus VP1 which does not contain the RGD motif. Vaccine 1999, 18:50-56.

16. Burman A, Clark S, Abrescia NG, Fry EE, Stuart DI, Jackson T: Specificity of the VP1 GH loop of Foot-and-Mouth Disease virus for alphav integrins. J Virol 2006, 80:9798-9810.
17. Fox G, Parry NR, Barnett PV, McGinn B, Rowlands DJ, Brown F: The cell attachment site on foot-and-mouth disease virus includes the amino acid sequence RGD (arginine-glycine-aspartic acid). J Gen Virol 1989, 70(Pt 3):625-637.

18. Robertson $\mathrm{BH}$, Morgan DO, Moore DM: Location of neutralizing epitopes defined by monoclonal antibodies generated against the outer capsid polypeptide, VP1, of foot-and-mouth disease virus A12. Virus Res 1984, 1:489-500.

19. Strohmaier K, Franze R, Adam KH: Location and characterization of the antigenic portion of the FMDV immunizing protein. J Gen Virol 1982, 59:295-306

20. Wild TF, Brown F: Nature of the inactivating action of trypsin on footand-mouth disease virus. J Gen Virol 1967, 1:247-250.

21. Baranowski E, Ruiz-Jarabo CM, Sevilla N, Andreu D, Beck E, Domingo E: Cell recognition by foot-and-mouth disease virus that lacks the RGD integrinbinding motif: flexibility in aphthovirus receptor usage. J Virol 2000, 74:1641-1647.

22. Fry EE, Lea SM, Jackson T, Newman JW, Ellard FM, Blakemore WE, AbuGhazaleh R, Samuel A, King AM, Stuart DI: The structure and function of a foot-and-mouth disease virus-oligosaccharide receptor complex. EMBO J 1999 , 18:543-554.

23. Jackson T, Ellard FM, Ghazaleh RA, Brookes SM, Blakemore WE, Corteyn AH, Stuart DI, Newman JW, King AM: Efficient infection of cells in culture by type $\mathrm{O}$ foot-and-mouth disease virus requires binding to cell surface heparan sulfate. J Virol 1996, 70:5282-5287.

24. Sa-Carvalho D, Rieder E, Baxt B, Rodarte R, Tanuri A, Mason PW: Tissue culture adaptation of foot-and-mouth disease virus selects viruses that bind to heparin and are attenuated in cattle. J Virol 1997, 71:5115-5123.

25. Duque H, LaRocco M, Golde WT, Baxt B: Interactions of foot-and-mouth disease virus with soluble bovine alphaVbeta3 and alphaVbeta6 integrins. J Virol 2004, 78:9773-9781.

26. Colston E, Racaniello VR: Soluble receptor-resistant poliovirus mutants identify surface and internal capsid residues that control interaction with the cell receptor. EMBO J 1994, 13:5855-5862.

27. Colston EM, Racaniello VR: Poliovirus variants selected on mutant receptor-expressing cells identify capsid residues that expand receptor recognition. J Virol 1995, 69:4823-4829.

28. Monaghan P, Gold S, Simpson J, Zhang Z, Weinreb PH, Violette SM, Alexandersen $\mathrm{S}$, Jackson T: The alpha(v)beta6 integrin receptor for Footand-mouth disease virus is expressed constitutively on the epithelial cells targeted in cattle. J Gen Virol 2005, 86:2769-2780.

29. Swaney LM: A continuous bovine kidney cell line for routine assays of foot-and-mouth disease virus. Vet Microbiol 1988, 18:1-14.

30. Weinacker A, Chen A, Agrez M, Cone RI, Nishimura S, Wayner E, Pytela R, Sheppard D: Role of the integrin alpha $v$ beta 6 in cell attachment to fibronectin. Heterologous expression of intact and secreted forms of the receptor. J Biol Chem 1994, 269:6940-6948.

31. Gianni T, Cerretani A, Dubois R, Salvioli S, Blystone SS, Rey F, CampadelliFiume G: Herpes simplex virus glycoproteins $\mathrm{H} / \mathrm{L}$ bind to cells independently of \{alpha\}V\{beta\}3 integrin and inhibit virus entry, and their constitutive expression restricts infection. J Virol 2010, 84:4013-4025.

32. Gianni T, Gatta V, Campadelli-Fiume G: \{alpha\}V\{beta\}3-integrin routes herpes simplex virus to an entry pathway dependent on cholesterol-rich lipid rafts and dynamin2. Proc Natl Acad Sci USA 2010, 107:22260-22265.

33. Xu X, Nagarajan $H$, Lewis NE, Pan S, Cai Z, Liu X, Chen W, Xie M, Wang W, Hammond S, Andersen MR, Neff N, Passarelli B, Koh W, Fan HC, Wang J, Gui Y, Lee KH, Betenbaugh MJ, Quake SR, Famili I, Palsson BO, Wang J: The genomic sequence of the Chinese hamster ovary (CHO)-K1 cell line. Nat Biotechnol 2011, 29:735-741.

34. Esko JD, Stewart TE, Taylor WH: Animal cell mutants defective in glycosaminoglycan biosynthesis. Proc Natl Acad Sci USA 1985, 82:3197-3201.

35. Esko JD, Weinke JL, Taylor WH, Ekborg G, Roden L, Anantharamaiah G, Gawish A: Inhibition of chondroitin and heparan sulfate biosynthesis in Chinese hamster ovary cell mutants defective in galactosyltransferase I. J Biol Chem 1987, 262:12189-12195.

36. Maree FF, Blignaut B, Aschenbrenner L, Burrage T, Rieder E: Analysis of SAT1 type foot-and-mouth disease virus capsid proteins: influence of receptor usage on the properties of virus particles. Virus Res 2011, 155:462-472.

37. Maree FF, Blignaut B, de Beer TA, Visser N, Rieder EA: Mapping of amino acid residues responsible for adhesion of cell culture-adapted foot-andmouth disease SAT type viruses. Virus Res 2010, 153:82-91. 
38. Lidholt K, Weinke JL, Kiser CS, Lugemwa FN, Bame KJ, Cheifetz S, Massague J, Lindahl U, Esko JD: A single mutation affects both $\mathrm{N}$ acetylglucosaminyltransferase and glucuronosyltransferase activities in a Chinese hamster ovary cell mutant defective in heparan sulfate biosynthesis. Proc Natl Acad Sci USA 1992, 89:2267-2271.

39. Esko JD, Rostand KS, Weinke JL: Tumor formation dependent on proteoglycan biosynthesis. Science 1988, 241:1092-1096.

40. Stephens RS, Poteralski JM, Olinger L: Interaction of Chlamydia trachomatis with mammalian cells is independent of host cell surface heparan sulfate glycosaminoglycans. Infect Immun 2006, 74:1795-1799.

41. Zhao QZ, Pacheco JM, Mason PW: Evaluation of genetically engineered derivatives of a Chinese strain of foot-and-mouth disease virus reveals a novel cell-binding site which functions in cell culture and in animals. J Virol 2003, 77:3269-3280.

42. Johns HL, Berryman S, Monaghan P, Belsham GJ, Jackson T: A dominantnegative mutant of rab5 inhibits infection of cells by foot-and-mouth disease virus: implications for virus entry. J Virol 2009, 83:6247-6256.

43. O'Donnell V, Larocco M, Baxt B: Heparan sulfate-binding foot-and-mouth disease virus enters cells via caveola-mediated endocytosis. J Virol 2008, 82:9075-9085.

44. O'Donnell CD, Shukla D: A novel function of heparan sulfate in the regulation of cell-cell fusion. J Biol Chem 2009, 284:29654-29665.

45. Neff S, Mason PW, Baxt B: High-efficiency utilization of the bovine integrin alpha(v) beta(3) as a receptor for foot-and-mouth disease virus is dependent on the bovine beta(3) subunit. J Virol 2000, 74:7298-7306.

46. Dicara D, Burman A, Clark S, Berryman S, Howard MJ, Hart IR, Marshall JF, Jackson T: Foot-and-mouth disease virus forms a highly stable, EDTAresistant complex with its principal receptor, integrin alphavbeta6: implications for infectiousness. J Virol 2008, 82:1537-1546.

47. Domingo E, Escarmis C, Martinez MA, Martinez-Salas E, Mateu MG: Footand-mouth disease virus populations are quasispecies. Curr Top Microbiol Immunol 1992, 176:33-47.

48. Mateu MG, Valero ML, Andreu D, Domingo E: Systematic replacement of amino acid residues within an Arg-Gly-Asp-containing loop of foot-andmouth disease virus and effect on cell recognition. J Biol Chem 1996, 271:12814-12819.

49. Rieder E, Baxt B, Mason PW: Animal-derived antigenic variants of footand-mouth disease virus type A12 have low affinity for cells in culture. J Virol 1994, 68:5296-5299.

50. Nunez JI, Martin MJ, Piccone ME, Carrillo E, Palma EL, Dopazo J, Sobrino F: Identification of optimal regions for phylogenetic studies on VP1 gene of foot-and-mouth disease virus: analysis of types $\mathrm{A}$ and $\mathrm{O}$ Argentinean viruses. Vet Res 2001, 32:31-45.

51. Weddell GN, Yansura DG, Dowbenko DJ, Hoatlin ME, Grubman MJ, Moore $D M$, Kleid DG: Sequence variation in the gene for the immunogenic capsid protein VP1 of foot-and-mouth disease virus type A. Proc Natl Acad Sci USA 1985, 82:2618-2622.

52. Logan D, Abu-Ghazaleh R, Blakemore W, Curry S, Jackson T, King A, Lea S, Lewis $\mathrm{R}$, Newman J, Parry N, et al: Structure of a major immunogenic site on foot-and-mouth disease virus. Nature 1993, 362:566-568.

53. Combet C, Jambon M, Deleage G, Geourjon C: Geno3D: automatic comparative molecular modelling of protein. Bioinformatics 2002, 18:213-214.

54. Borca MV, Pacheco JM, Holinka LG, Carrillo C, Hartwig E, Garriga D, Kramer E, Rodriguez L, Piccone ME: Role of arginine-56 within the structural protein VP3 of foot-and-mouth disease virus (FMDV) 01 Campos in virus virulence. Virology 2011, 422:37-45.

55. Ojosnegros S, Perales C, Mas A, Domingo E: Quasispecies as a matter of fact: Viruses and beyond. Virus Res 2011, In press.

56. Wells VR, Plotch SJ, DeStefano JJ: Determination of the mutation rate of poliovirus RNA-dependent RNA polymerase. Virus Res 2001, 74:119-132.

57. Li P, Lu Z, Bao H, Li D, King DP, Sun P, Bai X, Cao W, Gubbins S, Chen Y, Xie B, Guo J, Yin H, Liu Z: In-vitro and in-vivo phenotype of Asia1 foot-andmouth disease viruses utilizing two non-RGD receptor recognition sites. BMC Microbiol 2011, 11:1-12.

58. Gutierrez-Rivas M, Pulido MR, Baranowski E, Sobrino F, Saiz M: Tolerance to mutations in the foot-and-mouth disease virus integrin-binding RGD region is different in cultured cells and in vivo and depends on the capsid sequence context. J Gen Virol 2008, 89:2531-2539.

59. Rieder E, Henry T, Duque H, Baxt B: Analysis of a foot-and-mouth disease virus type A24 isolate containing an SGD receptor recognition site in vitro and its pathogenesis in cattle. J Virol 2005, 79:12989-12998.
60. Rieder E, Bunch T, Brown F, Mason PW: Genetically engineered foot-andmouth disease viruses with poly $(\mathrm{C})$ tracts of two nucleotides are virulent in mice. J Virol 1993, 67:5139-5145.

61. Fry EE, Newman JW, Curry S, Najjam S, Jackson T, Blakemore W, Lea SM, Miller L, Burman A, King AM, Stuart DI: Structure of Foot-and-mouth disease virus serotype A10 61 alone and complexed with oligosaccharide receptor: receptor conservation in the face of antigenic variation. J Gen Virol 2005, 86:1909-1920.

62. Guex N, Peitsch MC: SWISS-MODEL and the Swiss-PdbViewer: an environment for comparative protein modeling. Electrophoresis 1997, $18: 2714-2723$

63. Kaplan W, Littlejohn TG: Swiss-PDB Viewer (Deep View). Brief Bioinform 2001, 2:195-197.

doi:10.1186/1743-422X-10-2

Cite this article as: Lawrence et al:: Examination of soluble integrin resistant mutants of foot-and-mouth disease virus. Virology Journal 2013 $10: 2$.

\section{Submit your next manuscript to BioMed Central and take full advantage of:}

- Convenient online submission

- Thorough peer review

- No space constraints or color figure charges

- Immediate publication on acceptance

- Inclusion in PubMed, CAS, Scopus and Google Scholar

- Research which is freely available for redistribution 